\title{
A Puzzle for Evaluation Theories of Desire
}

How we evaluate things and what we desire are closely connected. In typical cases, the things we desire are things that we evaluate as good or desirable. According to evaluation theories of desire, this connection is a very tight one: desires are evaluations of their objects as good or as desirable. ${ }^{1}$ There are two main varieties of this view. According to Doxastic Evaluativism, to desire that $\mathrm{p}$ is to believe or judge that $\mathrm{p}$ is good. ${ }^{2}$ According to Perceptual Evaluativism, to desire that $\mathrm{p}$ is to perceive $\mathrm{p}$ as being good (or for $\mathrm{p}$ to seem good). ${ }^{3}$ The present paper poses a puzzle for such views. The puzzle should be familiar to theorists interested in the normativity and metaphysics of the emotions, but I am unaware of its application to desire. 4 The aim of the present paper is to present the puzzle as it applies to desire, which should be of independent interest, but I also hope that by shining a light on the puzzle in this domain, we might put ourselves in a better position to offer a

\footnotetext{
${ }^{1}$ There is room for debate about how the objects of desire are evaluated as being, for example, as good (for the subject/for oneself) or as desirable (for the subject/for oneself). The puzzle I will present gives rise to a recipe that can very easily accommodate choices. For ease of exposition, I will work with evaluations as good. Gregory $(2013,2017)$ argues that to desire to $\varphi$ just is to believe that you have normative reason to $\varphi$. The puzzle I will raise can be made to apply to this view as well. More below, but to generate the puzzle as applied to Gregory, focus on a pair such as the following: desiring to $\varphi$ while simultaneously judging that there are no normative reasons to $\varphi$.

${ }_{2}^{2}$ See, for example, Anscombe (1963), Davidson (1980), de Sousa (1974), and Raz (1999, 2010).

3 See, for example, Chang (2004), Hawkins (2008), Helm (2001), Johnston (2001), Oddie (2005), Scanlon (1998), Schafer (2013), Schapiro (2009), Stampe (1987), Tenenbaum (2007), and Wallace (1999).

4 Others have noticed that there is an issue facing Doxastic Evaluativists that looks analogous to Greenspan's (1988) argument from recalcitrance against Cognitivism about the emotions. See Döring and Bahadir (2017) for discussion. The typical move is to then retreat to Perceptual Evaluativism. One aim of the present paper is to show that even this retreat is unsuccessful.
} 
solution in all cases. At the end of the paper, I gesture towards a promising way ahead that departs from relying on contradictory contents.

\section{The Puzzle}

If one desires that one see their new love interest while simultaneously judging that seeing this person would not be good, one is, in some sense, inconsistent. The inconsistency is similar to the inconsistency one finds in cases where one fears a dog judged to be not dangerous or where one is angry with someone who one knows has done nothing wrong.5 These are cases that, in ordinary parlance, we describe as irrational. These pairwise attitudes are ones that, all else equal, one ought not be in simultaneously. That one ought not be in such pairs cries out for explanation. ${ }^{6}$

Let's flesh out the case a bit more. Our subject has been seeing someone new but things aren't going especially well. This new person disappears for stretches of time, sends ambiguous messages and signals, and behaves in generally untrustworthy ways. Our subject affirms that this person is manipulative and bordering on abusive. There is no good to be found in spending time with this new love interest. But our subject is glued to the phone, waiting for a message, waiting for any kind of contact, and very eager to see the new

5 The often-cited preliminary account comes from D'Arms and Jacobson (2003) who hold that a recalcitrant emotion is one that persists 'despite the agent's making a judgement that is in tension with it... A recalcitrant bout of fear, for example, is one where the agent is afraid of something despite believing that it poses little or no danger' (129).

${ }^{6}$ Those with a preference for internalism about rationality can add that the agent in question is in a position to detect the tension between the states. My own preference is for an externalist conception of rationality but this isn't a crucial assumption for the argument in the main text. For ease of exposition, I'll simplify by leaving off the rider 'being able to detect'. 
interest. Our subject wants to see the new love interest but judges that there is nothing, not even pro tanto, good in seeing this person. Life would be better if our subject could forget all about this person and move on, but sometimes we feel as though we just can't help ourselves. We are sometimes drawn to what we know is bad for us. The heart wants what the heart wants, Emily Dickinson tells us, and our subject just wants to see those three little dots turn into a warm text message and when the dots show up and disappear, our subject feels let down and frustrated.

Cases like this one might be rare but they are not impossible. One might recall Augustine's desire to do that which he deems sinful - to steal pears that he will only throw away. 7 Augustine's desire to do that which he deems evil (and so not good) is perverse but not impossible. ${ }^{8}$ And it is hard to see why we should think that one who judges there to be no good in seeing the manipulative love interest cannot also desire to see them. For present purposes the mere possibility of such cases is enough.

Now, if I found myself in the shoes of our subject, I'd hope to get my mental life back in order. Given how I judge things to be (and let's suppose my judgements are very well supported), seeing the love interest is not something for me to pursue - it makes no sense for me to desire their company. My desire is intuitively in tension with how I take goodness to be distributed. A comparison with the emotions may be helpful. One who learns that his neighbor was wrongly accused of stealing shouldn't be angry with the neighbor. When one remains angry, we say that the person is being irrational or inconsistent and that their

\footnotetext{
${ }_{7}$ See Augustine (400/1961, p. 49). For further discussion of this case see Tenenbaum (2018) and Velleman (1992).

${ }^{8}$ See Oddie (2005), Schafer (2013), and Tenenbaum (2018) for further discussion of such cases and attempts to accommodate them.
} 
reaction makes no sense. Similarly, one who judges things to have no good in them shouldn't want them. 9 "This person is constantly manipulating you and no one you trust thinks they are good for you and you even agree... that you want to spend time with this person is irrational!" There are many ways we might describe these cases in ordinary language - irrational, unreasonable, inconsistent. The aim of the present paper is, first, to argue that Evaluativist theories of desire struggle to capture this sense of tension and, second, to offer a way of accounting for what this normative conflict consists in.

\subsection{Perceptual Evaluativism}

Evaluation theories of desire look, on first glance, to be well positioned to offer an explanation of the cases. Start with Perceptual Evaluativism and focus on desiring that one see the love interest while judging that it is not the case that seeing the love interest would be (even pro tanto) good. We can represent those two attitudes as follows (where ' $J$ ' stands for the judging-relation, 'P' for the perceiving-relation, 's' for our subject, ' $l$ ' for the love interest, and where wedged-brackets create a name for a proposition or state of affairs):

$\mathrm{J}(s,<$ it is not the case $<$ 's seeing $l$ is good $>>$ )

$\mathrm{P}\left(s,<s^{\prime}\right.$ s seeing $l$ is good $\left.>\right)$

This representation makes perspicuous that there is a logically interesting relationship between the content of one's perception (which is one's desire on the view under consideration) and of one's judgement. We might then offer the following explanation of

\footnotetext{
9 The focus presently is not on cases in which one takes something to be not overall good but perhaps good in some way. Such cases are not puzzling in the same way as the case in the main text. One can consistently and rationally want something that one sees some good in even if, overall, it is deemed not good. For example, a judge who reluctantly sentences someone found guilty, as an anonymous referee helpfully suggests.
} 
the inconsistency we hope to capture: the logical inconsistency in content explains why it is that there is an inconsistency between the desire and the judgement.

Although superficially promising, this explanation fails. It is not the case that perceiving things to be one way while judging them to be another way constitutes an inconsistency of the sort we are hoping to explain. This is of course familiar from cases of illusion. I might look carefully at the stick submerged in water and correctly report that it looks bent to me. But I know better and judge that the stick is not bent. I am in no way irrational in such a case. In general, it is not the case that perceiving that $\mathrm{p}$ while judging that not-p constitutes the kind of inconsistency we are hoping to capture. When judgement and perception diverge, we might have good reason to get our eyes checked or get a bit more sleep, but we aren't blameworthy, inconsistent, or irrational when we undergo an illusion. So, the 'ought' we seek to explain cannot be explained if desire is reduced to perception. ${ }^{10,}{ }^{11}$ One

\footnotetext{
${ }^{10}$ It is worth noting that 'seemings' are no better. It is not irrational for things to seem one way while believing them to be otherwise.

${ }^{11}$ Oddie (2005, pp. 64-5) discusses the nearby case of one knowingly desiring to be evil. According to Oddie, Evaluativists can admit the possibility of such cases by taking the desire to be an experience as of something being good and he likens the case in question to the bent-stick illusion. Oddie seems to be sensitive to the fact that there is a problem for our subject here - he notes that there is a 'conflict' and that the desire is 'incompatible' with the belief. But, according to Oddie, what this comes to is that one cannot both hold the belief about the action being evil while also taking the experience of goodness to be reliable. But this isn't enough in my view. This likens the tension to the sort one finds in cases of illusion, but my point is that this isn't what's going wrong in the cases on which we are focused. There is no sense in which one who appreciates that an experience is delivering bad evidence while holding onto her belief is being 'irrational', 'inconsistent', or 'unreasonable'. We would in no way blame such a person. Now, our folk-reactions to the cases - the love interest, the case of desiring what's known to be evil, and cases of illusion - may not come with precise labels, but the folk-wisdom has it that there is a kind of normative conflict in the case of the love
} 
way of putting this is in terms of 'inconsistency transmitting' pairs of attitudes. ${ }^{12}$ Some pairs of attitudes are such that the subjects who are in them are themselves inconsistent when the contents of those attitudes contradict one another. But not all attitudes are like this. The pair belief/desire is not inconsistency transmitting, for example, since there is nothing inconsistent about believing things to be one way and wanting them to be exactly not that way. ${ }^{13}$ As an even simpler example, the pair supposition/belief is not inconsistency transmitting. One can suppose that $\mathrm{p}$ while believing that not-p without herself being inconsistent. But pairs of beliefs or pairs of judgements are inconsistency transmitting. When one believes that $\mathrm{p}$ and believes that not-p, one is thereby inconsistent. The perceptual evaluation theory falls short of making sense of our inconsistency given that the pair of judgement and perception are not inconsistency transmitting. Even though the belief that not-p and the perception that $\mathrm{p}$ have contradictory contents, a subject in that pair of states isn't thereby rationally on the hook for a mistake.

\subsection{Doxastic Evaluativism}

The foregoing is immediately suggestive. In order to explain the inconsistency in question, we should hold that desires are beliefs or judgements as of things being good rather than

interest and the desire for evil that is distinct from the tension one finds in cases of illusion. Below I'll say what exactly I think the conflict consists in, but at the moment it's enough to see that there is a difference. (And if Oddie's suggestion is that what's gone wrong in the case of desiring the evil is that one has judged the experiential evidence that $\mathrm{p}$ to be reliable but then also, all else equal, judged that not-p, then Oddie faces the problems in section 1.2 below.)

${ }^{12}$ See Schroeder (2008, p. 43).

${ }_{13}$ It is worth flagging exactly the difference between this case and our puzzling case. When ones believes (say) that it is Monday and simultaneously desires that it not be Monday, one is not thereby inconsistent. Inconsistency arises when one believes that it is not good (or desirable or ... choose your favorite view of the relevant property that helps analyze desire) that it is Monday while desiring that it be Monday nevertheless. 
perceptions. That is, we should adopt Doxastic Evaluativism. Such a theory does indeed allow us to maintain that the following pair of attitudes are inconsistent (since pairs of judgements are inconsistency transmitting): the judgement that seeing $l$ is good (which is one's desire according to the theory) and the judgement that it is not the case that seeing $l$ is good.

$\mathrm{J}(s,<$ it is not the case $<$ s's seeing $l$ is good $>>)$

$\mathrm{J}(s,<$ s's seeing $l$ is good $>)$

This is promising, but it isn't the correct solution. On the doxastic evaluation theory, our subject judges that $\mathrm{p}$ and judges that not-p. But compare the subject we wish to capture with one who affirms that grass is green and, in but another breath, denies that it is green. Or compare our subject to one who holds that $2+2=4$ and simultaneously holds that it is not the case that $2+2=4$. Indicting our subject of outright contradictions in belief or judgement looks to be a misdescription of the case. There are a number of ways one might go on to substantiate this verdict. Allow me to sketch three forthcoming ways, (though what's important is simply that, for whatever reason one might give, the Doxastic Evaluativist misdescribes the cases under consideration). First, in but one step, a subject could deduce from the two beliefs just mentioned that grass is both green and not green. But affirming that proposition looks to be a simple logical mistake. Subjects in the cases we are focused on aren't making simple logical errors. Second, one might point out that while desires (and presumably emotions) are not activities of ours, beliefs and judgements are and so are subject to more demanding rational standards. As Boyle (2009) argues, beliefs and judgements are exercises of 'rational self-determination'. Desires (and emotions) are governed by norms - more on this below - but not in the same way or to the same degree as our activities. Third, following Helm's (2015) discussion of recalcitrant emotion and 
Cognitivism, we might hold that attributing clear-eyed contradictions to subjects would make them uninterpretable when they in fact are not. When we try to interpret or rationalize a subject with contradictory beliefs or judgements, as Helm (2015) puts it, the 'mind boggles'. It is helpful to consider this claim with a more detailed case (due to Stitch (1981) and Dennett (1987) but helpfully recounted by Helm (2015)):
A boy is selling lemonade at a stand with a sign that "says 'LEMONADE-12 cents a glass.' I hand him a quarter, he gives me a glass of lemonade and then a dime and a penny change. He's made a mistake," and yet when this is pointed out to him, he sincerely denies that it is a mistake. At this point we might try to interpret him more carefully to discover precisely what mistake he has made. Perhaps he thinks he's selling lemonade for $14 \$$ a glass or that a quarter is worth $23 \notin[\ldots]$ and yet as we question him further it becomes clear that he has all the relevant true beliefs except that he insists, quite sincerely and honestly, that he has not made a mistake. At this point, the mind simply boggles: there is no coherent way of describing what he believes or intends, and so no single, best way to understand precisely what mistake he has made. (424-5)

But one who wants to see $l$ while judging that it would not be good is not mind boggling. A person like this is inconsistent but is not incoherent. Given one's beliefs, one shouldn't have the desire to see the manipulator, but to so desire is not uninterpretable.

Any one of the above three lines leads to the same conclusion: Doxastic Evaulativism is guilty of over indictment.

\subsection{The Puzzle Summarized and Generalized}


On the one hand, we have a theory of desire (Perceptual Evaluativism) that seems to predict no rational failing in the case under consideration. On the other hand, we have a theory of desire (Doxastic Evaluativism) that over indicts and so predicts the wrong kind of failing.

It is worth highlighting that the puzzle as presented provides a recipe that easily scoops up variations in cases. The puzzle turns on the following structure:

\begin{abstract}
Assume that a subject desires $o$ and assume that the subject believes/judges that it is not the case that $o$ is $\mathrm{F}$. An evaluativist will either incorrectly predict that the subject is not inconsistent (by analysing desire in terms of a non-inconsistencytransmitting attitude) or will over indict the failing (by analysing desire in terms of an inconsistency-transmitting attitude).
\end{abstract}

In light of this structure, various styles of reply will be very difficult to run. For example, suppose that one objected to the above by pointing out that there is nothing inconsistent in believing that something is not good in some respect while desiring that thing, provided that one's desire represents it as good in a different respect. Although on first glance this is a promising approach, this will not allow one to side-step the puzzle. Substitutions for ' $F$ ' in the structure above are left wide open. The only constraints are that it be a sensible candidate for an Evaluativist to utilize in their theory and that it be a property that one can have beliefs/judgements about. An Evaluativist can fill in any property - being good, being desirable, being a normative reason to $\varphi$ - and we can then easily stipulate a case in which one has the right belief/judgement to land in trouble. The puzzle is very flexible in its application. 
The upshot of the above is that neither belief nor perception is the right attitude in terms of which to analyze desire. One way out of the puzzle might be to find an alternative attitude relation that gets the incoherence just right. That is, an attitude-relation that allows one to build an evaluative property into the content of desire while yielding just the right type and degree of conflict with judgements whose contents contradict the now imagined attitude. But I'm skeptical that there is any such relation since I'm unaware of any pair of attitudes that are both inconsistency transmitting and which do not bring us back into the territory of over indictment. Judgement and hope? Not inconsistency transmitting. Judgement and supposition? Not inconsistency transmitting. Judgement and knowledge? Over indictment. It's hard to see where to turn.

\section{Fit and Misfit}

Attitudes can be assessed for being merited or fitting. For example, fear directed towards a dangerous thing is fitting but fear directed towards a harmless thing is unfitting. Lovable things merit being loved and amusing things merit amusement. ${ }^{14}$ And so on. According to some theorists, fittingness is a primitive normative notion that one can use to explain other normative notions. Alternatively, one might think that fittingness is to be explained in other terms - in terms of value or in terms of reasons perhaps. ${ }^{15}$ I remain non-committal on these choices. The important point is that attitudes can be fitting or unfitting, be that a fundamental fact or not.

\footnotetext{
${ }^{14}$ I'll use the terms 'fit' and 'fittingness'. Other terms that appear in the literature and aim to capture the same phenomena are, as mentioned, 'merit' but also 'correct', 'appropriate', and 'worthy'.

${ }_{15}$ For recent discussions of fittingness and the possibility that fit might be a primitive in our normative theorising, see McHugh and Way (2016) and Yetter Chappell (2012). For an overview of fittingness see Howard (2018).
} 
When it comes to accounting for the conflicts above, my suggestion is that we depart from telling a story in terms of contradictions in content and rely on a new notion I will call 'misfit'. Let's return to the subject who desires to see the love interest but believes that there is no good in it.

Desires for good things are fitting but desires for non-good things are not. So, if one desires something that is not good, they are responding to an object in an unfitting way (as was implicit above, 'object' is construed broadly).

Beliefs can also be assessed for fittingness: true beliefs are fitting and false beliefs are unfitting. Or, in alternative terms, truths merit belief. But now suppose that one believes that it is not the case that seeing $l$ is good. Such a belief is fitting just in case it is not good to see 1 .

Notice that the belief that it is not the case that seeing $l$ is good interfaces in an interesting way with the desire to see $l$. If the desire to see $l$ is fitting (because seeing $l$ is good), the belief that it is not the case that seeing $l$ is good will be unfitting. On the other hand, if the belief is fitting the desire will be unfitting. The pair of believing that it is not the case that seeing $l$ is good and desiring to see $l$ is a pair that guarantees that one will be responding to the world unfittingly.

Call such pairs 'misfits'. We can say something more general about misfits. In order to do so let us say that attitudes that can be assessed for fittingness correspond to a 'fit property'. For example, the fit property of fear is dangerousness and the fit property of desire is goodness. To bear a fitness-assessable attitude towards something that instantiates that 
attitude's fit property is to respond to that thing in a fitting way. With fit properties in hand, we can say which beliefs interact with desires (and indeed with emotions) in a way that is guaranteed to yield fittingness violations. We can say which attitude pairs are misfits:

Misfit: A fittingness assessable attitude towards $o$ that has fit-property $\mathrm{P}$ forms a misfit with a belief/judgement just in case the belief/judgement represents that it is not the case that $o$ is $\mathrm{P}$.

Pairs of belief/desire and belief/emotion that adhere to this description are such that one who is in the pair of states is bound to be in at least one unfitting state. And this is precisely the sense in which misfits are inconsistent. The inconsistency of misfits is a modal fact to the effect that one is guaranteed to fail at fit. Our case presents a case of misfit. Either one's judgement is unfitting or one's desire is unfitting and so one is sure to fail. And this explains the folk wisdom according to which subjects in such pairs of states are 'irrational', 'unreasonable', 'inconsistent', or guilty of 'making no sense'.

At this juncture it may be tempting to think that the notion of a misfit doesn't add anything new to what Evaulativists offer. An Evaluative theorist might react as follows:

On my view, to desire something is to represent it to be good. When the content of that state is false, the desire is unfitting. And if one believes the negation of that content, the belief is fitting only if the content is true. So I too can help myself to the misfit approach and on my view misfits occur when the contents contradict. So what's new about Misfits? 
The Evaluativist interlocutor doesn't quite have things right. The Evaluativist view is that when one desires something, one (in some way or other) represents it as good. But what exactly is the representation relation that one stands in to the content that (say) stealing is good? Whatever the relation (belief, judgement, perception, something else?), it must be such that it rationally conflicts with a judgement that stealing is not good. But we have seen above that taking the relation to be belief/judgement or perception runs into trouble and it's hard to see where else to turn. And the upshot, I am now suggesting, is that contradictory content all on its own is not the right place to start. If one tries to explain the rational failure by noting the contradictory contents andand then aims to explains the rational failure in those terms, one will misdescribe. Rather, Evaluativists should take on board the idea of Misfit and should not attempt to reduce Misfit to contradiction in content. Evaluativists are more than welcome to continue to hold that an individual desire is fitting only when it correctly represents, ${ }^{16}$ but Misfit is a pair-wise notion and it cannot be reduced to contradiction in content. The suggestion presently is that being misfitting should be added to our list of ways in which the mind can come into conflict.

\section{Acknowledgement}

\footnotetext{
${ }^{16}$ There is a noteworthy bonus. Not all theorists wish to account for the fittingness of desire in terms of representational content. Schafer (2013) argues that the aim of desire should be accounted for in terms of force not content. Tenenbaum (2018) argues for something similar holding that goodness is connected to the attitude rather than the content. One findss a similar move in Deonna and Teroni (2015) who argue that value properties are relevant to the emotions qua attitudes and not in terms of their contents. ,Misfit is applicable to these views and it allows one to say why desires and emotions conflict with certain judgements even without attributing propositional content to the desires. One might have thought that without a propositional content one couldn't accommodate the conflict in our case and in recalcitrant emotions, but Misfit shows that this isn't so.
} 
Thanks to Mark Balaguer, Peter Hanks, Guha Krishnamurthi, Eric Vogelstein, Jeremy Schwartz and to an audience at Birkbeck for helpful discussions on this topic. Special thanks to Alex Gregory for comments on an earlier draft and thank you to the editors and referees at Thought for their comments and feedback. 


\section{References}

Anscombe, G. E. M. (1963): Intention. 2nd edition. Oxford: Blackwell.

Augustine (400/1961) Confessions, edited by Pine-Coffin RS. Penguin Books, Baltimore.

Boyle, Matthew (2009). Active Belief. Canadian Journal of Philosophy 39 (S1):119-147.

Chang, Ruth (2004): “Can Desires Provide Reasons for Action?” Reason and Value:

Themes from the Moral Philosophy of Joseph Raz. Eds. R Jay Wallace, Philip Pettit, Samuel Scheffler, and Michael Smith. Oxford: Oxford University Press. 56-90.

Chappell, R. Yetter (2012). 'Fittingness: The sole normative primitive'. Philosophical Quarterly 62 (249):684-704.

Davidson, Donald (1980): “Actions, Reasons, and Causes.” Essays on Actions and Events. Oxford: Clarendon Press. 3-19.

Deonna, Julien A. \& Teroni, Fabrice (2015). Emotions as Attitudes. Dialectica 69 (3):293-311.

Dennett, Daniel C. (1987). "Making Sense of Ourselves.” In The Intentional Stance (Cambridge, MA: MIT Press), 83-101. de Sousa, Ronald (1974): “The Good and the True.” Mind 83. 534-551.

Döring, Sabine \& Eker, Bahadir (2017). Desires without Guises: Why We Need Not Value What We Want. In Julien Deonna \& Federico Lauria (eds.), The Nature of Desire. Oxford University Press.

Greenspan, Patricia S. (1988). Emotions and Reasons: An Inquiry into Emotional Justification. London: Routledge.

Gregory, Alex (2013). The Guise of Reasons. American Philosophical Quarterly 50 (1):63-72.

-(2017). Might Desires Be Beliefs About Normative Reasons? In Julien Deonna \& Federico Lauria (eds.), The Nature of Desire. Oxford University Press. pp. 201-217. Helm, Bennett (2001). Emotional Reason: Deliberation, Motivation, and the Nature of 
Value. Cambridge: Cambridge University Press.

-(2015). 'Emotions and Recalcitrance: Reevaluating the Perceptual Model'. Dialectica 69.3, pp. 417-33.

Howard, Christopher (2018). 'Fittingness'. Philosophy Compass 13 (11):e12542. Johnston, Mark(2001). "The Authority of Affect." Philosophy and Phenomenological Research 63. 181-214.

Lauria, Federico \& Deonna, Julien (eds.) (2017). The Nature of Desire. New York, USA: Oxford University Press.

McHugh, C. and Way, J. (2016). Fittingness First. Ethics 126 (3):575-6o6.

Oddie, Graham (2005). Value, Reality, and Desire. Oxford: Oxford University Press.

Raz, Joseph (1999). Engaging Reason: On the Theory of Value and Action. Oxford: Oxford University Press.

-(2010). "On the Guise of the Good." Desire, Practical Reason, and the Good. Ed. Sergio Tenenbaum. Oxford: Oxford University Press. 111-137.

Schafer, Karl (2013). "Perception and the Rational Force of Desire." Journal of Philosophy 110. $258-281$.

Scanlon, Thomas M. (1998). What We Owe to Each Other. Cambridge, MA: Harvard University Press.

-(2002): “Replies." Social Theory and Practice 28. 337-358.

Schapiro, Tamar (2009). “The Nature of Inclination.” Ethics 119. 229-256.

Schroeder, Timothy (2004). Three Faces of Desire. Oxford: Oxford University Press. -(2014). "Desire.” The Stanford Encyclopedia of Philosophy (Spring 2014 Edition). Ed. Edward N. Zalta. <http://plato.stanford.edu/archives/spr2014/entries/desire/>. Schueler, George F. (1995). Desire: Its Role in Practical Reason and the Explanation of Action. Cambridge, MA: MIT Press.

-(2003). Reasons and Purposes: Human Rationality and the Teleological Explanation of 
Action. Oxford: Oxford University Press.

Stampe, Dennis W. (1987): “The Authority of Desire.” Philosophical Review 96. 335-381.

Stich, Stephen P. (1981). “Dennett on Intentional Systems.” Philosophical

Topics, 12(1), 39-62.

Tenenbaum, Sergio (2007). Appearances of the Good: An Essay on the Nature of Practical Reason. Cambridge: Cambridge University Press

-(2013): "Guise of the Good." The International Encyclopedia of Ethics. Ed. Hugh LaFollette. 1-9.

-(2018). The Guise of the Guise of the Bad. Ethical Theory and Moral Practice 21 (1):5-20.

Velleman, David. (1992). "The Guise of the Good.” Nous 26(1):3-26

Wallace, R. Jay (1999): “Addiction as Defect of the Will: Some Philosophical Reflections.” Law and Philosophy 18. 621-654. 